\title{
A RETÓRICA DOS VÍNCULOS NO ROCK IN RIO
}

\author{
Rhetoric of bonds in Rock in Rio
}

\section{La retórica de los lazos en Rock in Rio}

Thiago Soares ${ }^{1}$

\section{Resumo}

Delineia-se o esboço de um aporte conceitual para compreender o que chamamos de retórica dos vínculos entre organizações e marcas nos eventos. Determina-se três tipologias: aquelas angariadas sobre a retórica do logos (razão/retorno econômico), do pathos (emoção/dinâmicas simbólicas) e do ethos (ética/plataformas de ações sustentáveis). Rascunha-se uma breve análise tomando como materialidade interpretativa o evento Rock in Rio, ocorrido em 2011.

Palavras-chave: eventos, metodologias de análise, retórica.

\begin{abstract}
This article aims to create a conceptual contribution to understand what we call rhetoric of bonds between organizations and brands in events. There are three types of linkages: the rhetoric of logos (reason/ economic return), pathos (emotion/ symbolic dynamics) and ethos (ethical / sustainable actions platforms). A brief analysis tries to understand the rhetoric of bonds in Rock in Rio, which occurred in 2011.
\end{abstract}

Keywords: events, methods of analysis, rethoric.

\section{Resumen}

Este artículo tiene como objetivo crear una contribución conceptual para entender lo que llamamos retórica de los lazos entre las organizaciones y marcas en eventos. Hay tres tipos de lazos: la retórica de logos (razón / retorno económico), pathos (emoción / dinámicas simbolicas) y ethos (ética / plataformas sostenible de acciones). Una breve

\footnotetext{
${ }^{1}$ Professor do Programa de Pós-Graduação em Comunicação e Culturas Midiáticas da Universidade Federal da Paraíba (UFPB), doutor em Comunicação e Cultura Contemporâneas pela Universidade Federal da Bahia (UFBA), coordenador do grupo de pesquisa em Mídia, Entretenimento e Cultura Pop (Grupop) na UFPB. E-mail: thikos@uol.com.br.
} 
análisis trata de comprender la retórica de los lazos en Rock in Rio, que ocorrió en 2011.

Palabras-clave: eventos, metodologías de análisis, retórica.

Não há muita novidade em alardear que o Brasil viverá, pelo menos, até 2016, um período profícuo de eventos, sejam eles grandes festivais de música capazes de mobilizar multidões (como as 700 mil pessoas em 98 horas de Rock in Rio, no ano de 2011, e que já tem edição agendada para 2013) ou mesmo eventos esportivos (como a Copa do Mundo, em 2014, e os Jogos Olímpicos do Rio de Janeiro, em 2016). Também não é preciso esforço para reconhecer que parte da "eclosão" destes eventos se dá em função da estável economia brasileira, do contexto de emergência do Brasil como agente das relações político-econômicas num mundo que assiste à consolidação do BRIC (Brasil, Índia, Rússia e China) e a instabilidade de mercados tradicionalmente norteadores da economia mundial, como os Estados Unidos e a União Européia.

O Brasil sai de sua condição de invisibilidade nos mercados mundiais a partir de uma retranca essencialmente econômica: políticas públicas atenuam a pobreza, acontece o aumento do poder de consumo das classes C e D e a consolidação de uma classe média com capacidade de fruição de produtos culturais. Este contexto de lugares-comuns já amplamente divulgados pela imprensa nos aciona para uma questão que parece fundamental de ser debatida nos fóruns acadêmicos transdisciplinares de Comunicação em Contextos Organizacionais, Publicidade e Propaganda, Marketing, Administração, entre outros: estes eventos se configuram em importantes objetos empíricos capazes de evocar hipóteses de pesquisa que norteiem e evidenciem as transformações das organizações, dos contextos culturais, das lógicas de produção e consumo e dos vínculos entre instâncias do marketing e da economia.

Pensar o evento como ponto de partida de investigação significa acenar para a necessidade de metodologias de análise $^{2}$ capazes de compreendê-lo em suas

\footnotetext{
2 Tratando de maneira mais precisa, trata-se do que se convencionou chamar de Metodologias Empíricas da Comunicação. A denominação visa enquadrar trabalhos de cunho teórico-analíticos que se dirigem a objetos empíricos delimitados - no nosso caso, o evento - buscando uma forma de reflexão que problematize seus elementos constitutivos. Estamos diante da bifurcação de uma metodologia da pesquisa e de uma metodologia na pesquisa: a nossa proposta é tanto indicar um domínio "do estudo dos métodos de uma ciência particular" quanto a construção de uma perspectiva de "aplicação desses métodos numa determinada pesquisa". (LOPES, 2005: 98) Ou seja, estamos construindo alicerces de aportes metodológicos que se orientam a uma prática metodológica.
} 
dimensões discursivas. Quando nos referimos a uma metodologia de análise, estamos nos afastando de uma certa tradição de excessiva descrição em forma quase de "manual" do que deve "ter ou não ter" num evento. A ideia aqui não é simplesmente elencar tópicos que precisam ser cumpridos como etapas de elaboração de um evento - embora saibamos na necessidade de instrumentalização destas etapas e do importante papel que os manuais têm como disseminadores de regras do bem-fazer. Tampouco, a nossa premissa visa trabalhar com as pesquisas de opinião e entrevistas, averiguações de resultados de eventos - e também temos ciência da importância destes artefatos e da vasta contribuição que estudos prévios já nos concederam.

A ideia é tomar o evento, antes de tudo, como um discurso sobre: um entrelugar no qual é possível observar os movimentos que o originaram, seus vetores de encenação e performatização das organizações e também os públicos para os quais se orientam. O evento, em si, é uma espiral atravessada por estratégias, intenções, jogos de poder, inclinações políticas, econômicas, disposições estéticas. Portanto, nossa reivindicação é a de que o evento precisa ser investigado enquanto dimensão de um discurso que encena uma organização, uma marca, um cliente. Performatiza ambientes, conteúdos simbólicos, formas de engajamento.

Feito este breve preâmbulo, é importante demarcar que este texto se configura na apresentação de um aporte conceitual que está sendo "testado" para ajudar numa análise de ordem discursiva do evento: a noção de "retórica dos vínculos". Debateremos a gênese conceitual deste aporte, suas vinculações teóricas e faremos esboços de análise tomando como objeto o evento Rock in Rio, ocorrido em setembro e outubro de 2011, no Rio de Janeiro. Antes, no entanto, precisamos determinar o status do evento como um objeto empírico da Comunicação.

\section{O EVENTO COMO ENUNCIADO}

É no sentido de partir da análise empírica de eventos para a formatação de hipóteses de pesquisa em campos transdisciplinares do conhecimento, que este artigo arregimenta suas questões colocando em evidência um dispositivo de ordem hermenêutica: o evento deve ser pensado como objeto da Comunicação. Evocamos, aqui, a dupla via no que se convencionou chamar de epistemologia da Comunicação: uma que reconhece a Comunicação, em si, como objeto de investigação (seus processos, agentes, dispositivos, etc) e outra que tenta localizar objetos capazes de 
“dizer” sobre a Comunicação. São dois movimentos de interpretação: o primeiro, que parte do reconhecimento de processos macro, de idéias mais subjetivas que podem ser verificadas em materialidades empíricas, e o segundo, devoto da investigação do micro, da particularidade empírica em direção a postulados mais amplos. É neste segundo momento que nossas questões têm ponto de partida: o evento passa a ser uma materialidade empírica, algo capaz de nos fazer compreender postulações mais amplas, de ordens institucionais, econômicas, políticas e culturais. Tomá-lo como um objeto de investigação significa reconhecer que disposições de ordens discursivas e culturais emanam de sua materialização.

Este esboço de método visa rascunhar questões capazes de nortear a pesquisa, investigação e análise de eventos como um dos alicerces sobre hipóteses para pesquisas desenvolvidas no Programa de Pós-Graduação em Comunicação (PPGC) da Universidade Federal da Paraíba (UFPB) ${ }^{3}$ e se ancora em postulações que transitam por uma observação de ordem semiótica (aquela que discute linguagem, discurso e estratégias) atrelada a um olhar também culturológico (pensando que linguagem, discurso e estratégias estão circunscritos a contextos culturais que precisam ser compreendidos como fundamentais no agendamento das formatações dos eventos). Voltamos ao ponto de partida sobre o evento como objeto de investigação: dispositivos teóricos oriundos de uma tradição semiótica nos ajudam a compreender o que é o evento, a sua motivação, a descrição de sua natureza estrutural (de onde ele parte na engrenagem organizacional), que agentes são responsáveis por sua idealização, produção, execução e averiguação de resultados, a quem se destina, que dispositivos materiais o originam, que espaços o ancoram, que estratégias comunicacionais estão em jogo.

Um olhar mais semiótico nos desperta para a ligação premente que existe entre as condições de produção (VERÓN, 1996, 2004) e as condições de reconhecimento (que prefiro chamar aqui como condições de fruição ${ }^{4}$ ) num evento, apontando para a ideia de que investigar condições de produção significa entender o

\footnotetext{
${ }^{3}$ Trata-se de uma pesquisa em andamento denominada "Utopias Midiáticas" que visa estudar, entre outras disposições performáticas, os eventos como parte integrante e constitutivo de espacialidades ideais e, portanto, utópicas. Parte-se de um processo contínuo de investigação que teve início em 2011, na orientação de trabalhos sobre festivais de música e cultura jovem.

${ }^{4}$ Aqui faço uma crítica ao conceito de reconhecimento do teórico Eliseo Verón, uma vez que a noção de reconhecimento está atrelada ao assujeitamento do indivíduo em se engajar nos discursos compartilhados. Prefiro adotar o termo fruição (ao invés de reconhecimento) porque considero que sua terminologia nos empresta uma ideia de uso, experiência.
} 
lugar do evento na cultura organizacional, seu universo de práticas, de formas de fazêlo "funcionar" e consequentemente na sua formatação enquanto um dispositivo estratégico. As condições de fruição se articulam ao olhar mais culturológico, aquele que tenta dar conta dos agendamentos contextuais, das formas culturais prementes com os quais os eventos dialogam e engendram a própria dimensão da cultura de uma localidade, um continente, um país, uma cidade, etc.

Ao destacarmos as noções de condições de produção e de fruição inspiradas no pensamento de Eliseo Verón, não queremos, contudo, "separar" a atividade de análise de eventos sob duas retrancas: produção e fruição. A produção de um evento opera sobre os preceitos de um determinado tipo de fruição, de uma experiência. Desde a sua gênese, um evento é pensado também sobre uma forma de ser experienciado, "sentido", fruído. Por isso, não se deve pensar uma análise de evento, por exemplo, "separando" a produção da fruição.

O que propomos na observação analítica de um evento é a visualização do processo de produção discursiva, ou seja, o entendimento de que uma análise deve partir de conjuntos significantes dados no objeto comunicacional (o evento) e que é preciso, a partir destes dados observados, retomar o processo de produção. Naturalmente, falar sobre o processo de produção sugere a ideia de extensão e espraiamento entre a condição de produção do evento e, de fato, aquilo que se apresenta, se materializa. Estas dimensões são extensivas e abrem possibilidades de visualizações do "entre" produção e materialização.

Dessa forma, a nossa proposta de interpretação nos direciona para o evento como um objeto em sua configuração enunciativa. Se, nos pressupostos de Benveniste (1989, 1991), a enunciação corresponde a uma situação de discurso, atualização da atividade conjunta de locutor (produtor) e interlocutor (fruidor), pensamos o evento sob esta égide: a de que estamos diante de um enunciado que corresponde a uma ativação daquele que fala (organização/marca), no momento em que fala (cenário do evento e contexto cultural) e para quem fala (públicos/opinião pública). Fatores e atos provocam um enunciado e, portanto, ao tomarmos o evento como um enunciado em que estão em jogo condições de produção e de fruição, estamos em busca de uma certa produção de sentido do evento, nos enlaces capazes de gerar hipóteses sobre posicionamentos e enquadramentos. Tendo apresentado brevemente os pressupostos que norteiam a nossa observação analítica dos eventos, partimos para a apresentação 
do aporte conceitual que serve como chave interpretativa para nossas questões, a ideia de retórica dos vínculos.

\section{POR UMA RETÓRICA DOS VÍNCULOS}

Um dos pontos centrais para uma observação analítica sobre discursos que emanam de eventos se configura no que chamamos de retórica dos vínculos. Trata-se de um aporte conceitual rascunhado a partir de questões evocadas na análise prévia de eventos e desenvolvido dentro das discussões do Grupo de Estudo em Mídia, Entretenimento e Cultura Pop do Programa de Pós-Graduação em Comunicação (PPGC) da Universidade Federal da Paraíba (UFPB). O ponto de partida para a necessidade de formatação de um conceito desta natureza foi a premissa de que um evento só é possível de ser realizado a partir da confluência de esforços e, consequentemente, de interesses de organizações e marcas que encenarão suas estratégias nos espaços performatizados. A partir do pensamento político dos Estudos Culturais, refletir sobre as aproximações entre organizações significa reconhecer espaços estratégicos, formas de vinculações que visam justapor interesses de visibilidade, midiatização e posicionamento (MICKEY, 1997). A inspiração de ordem culturológica demanda a compreensão de que todo movimento em torno das organizações e de suas formas de visualização midiáticas deve ser entendido sob uma esfera de ordem político-econômica. Articulações que se encenam sobre os holofotes midiáticos e se alinham a uma máxima, por exemplo, comumente vista no campo dos regimes de políticas internacionais.

Observar as vinculações de organizações nos aciona compreender um contexto em que, cada vez mais, notamos um mundo regido por blocos, sejam eles econômicos, políticos ou culturais. Este movimento de observação dos vínculos entre organizações e marcas que propomos, nada mais é do que a materialização de uma observação que cientistas políticos e analistas/articuladores das relações internacionais já realizam: o que motiva, por exemplo, a união de países em torno de retrancas como Mercosul, União Européia ou BRIC? Que determinações estratégicas existem neste tipo de aproximação e vinculação? Que tipo de retorno políticoinstitucional, por exemplo, o Brasil tem ao se alinhar a países vizinhos no Mercosul? Quais implicações econômicas e políticas são acionadas para compreender a relação 
de uma Grécia em crise com os países da União Européia? Por que o mundo se organiza em conglomerados? Em vinculações?

Este movimento também pode ser visto nas organizações. A junção de corporações tendo em vista o fortalecimento de uma marca, a competitividade de mercado e a gestão de crises também contribui para que consigamos compreender as dimensões discursivas dos vínculos. A união dos bancos Itaú e Unibanco, a supressão da marca Unibanco e a decisão de "manter" a marca Itaú, por exemplo, é um caso em que exemplifica as dinâmicas de "blocagens" tão comuns no universo corporativo. A união entre as companhias aéreas TAM e Lan gerando uma companhia aérea de alto poder de competitividade na América Latina e mantendo, por enquanto, as duas marcas, também se configura numa natureza de vinculação corporativa que pode ser compreendida dentro de uma "nova ordem" das organizações.

Os exemplos de ordem político-econômicos entre países e de natureza corporativa são movimentos que observamos e que motivam um olhar mais detido sobre os eventos como espaços para a compreensão dos vetores de forças e estratégias que regem a aproximação entre marcas e organizações. Por isso, apontamos para a necessidade de construção de um aporte conceitual que acione no analista o questionamento acerca das naturezas de vínculos que se constroem nos eventos. A questão que levantamos ao propormos a noção de "retórica dos vínculos" se origina na compreensão de que estes alinhamentos corporativos são discursos encenados, performatizados e que precisam ser entendidos a partir de uma dimensão que é própria do terreno das linguagens.

Por isso, a volta ao estudo da retórica, aquela evocada por Aristóteles e que se configura na "arte/técnica de bem falar", do artifício do uso da linguagem para comunicar de forma eficaz e persuasiva. Pensar uma retórica dos vínculos institucionais significa acrescentar questões já estudadas no campo da Comunicação em Contextos Organizacionais, como as pesquisas sobre retórica de multinacionais (HALLIDAY, 1987) e retórica das organizações (BORGES, 2005), entre outros. Uma retórica dos vínculos pressupõe entender que a aproximação entre organizações e marcas num evento se inclina em três eixos: 1. Retórica de vínculos a partir do logos; 2. Retórica de vínculos a partir do pathos e 3. Retórica de vínculos a partir do ethos. A descrição e os questionamentos sobre as dimensões e os limites deste aporte conceitual podem ser compreendidos no momento de embate entre o conceito e 
pragmática de análise. É preciso, portanto, compreender os três eixos das retóricas dos vínculos. Vamos a eles.

a) Retórica dos vínculos a partir do logos: a noção de logos em "A Arte da Retórica", de Aristóteles, nos convoca ao entendimento do uso da razão e do raciocínio, quer indutivo ou dedutivo, para a construção de um argumento. Os apelos ao logos incluem recorrer à objetividade, estatística, matemática, lógica, raciocínio indutivo (utilização de exemplos históricos, míticos ou hipotéticos para conclusões) e raciocínio dedutivo. Configuram, portanto, num tipo de vinculação que evoca, naturalmente, a ideia de um “retorno" material, objetivo, financeiro. A noção de uma retórica dos vínculos a partir do logos nos convoca compreender as aproximações entre instituições, primeiramente, a partir de uma premissa econômica: que retorno financeiro há neste tipo de vínculo? De que maneira, a união vai reger ditames de ordens econômicas para as instituições? A performatização de vínculos entre marcas a partir da noção de logos de Aristóteles, nos convoca a investigar a natureza econômica das instituições e também o macro-contexto da economia em que estão inseridas.

b) Retórica de vínculos a partir do pathos: de acordo com Aristóteles, a projeção de um discurso a partir da retórica também se dá diante de apelos de ordens emocionais com o intuito de convocar o julgamento do público. O pathos se configura nas lógicas das paixões, dos impulsos, uma vez que, na sua etimologia, a palavra é de origem grega e também significa excesso, catástrofe, passagem, sofrimento e assujeitamento. O conceito filosófico de pathos foi cunhado para designar tudo o que se faz ou acontece de novo, além, logicamente, de mobilidade e imperfeição. O pathos nos convoca a retórica que se emana do embelezamento das formas de dizer, do uso de metáforas e outras figuras de linguagens. A noção de uma retórica dos vínculos a partir do pathos nos aciona compreender as aproximações entre instituições diante de um quadro que apela para dispositivos emocionais e eminentemente simbólicos. Instituições se vinculam a outras não somente em função de ganhos econômicos, lógicas de excessiva racionalidade. O "empréstimo" emocional dos discursos de marcas, assim como, as estratégias de performatização afetiva de instituições são embates constantemente visualizados em eventos.

c) Retórica de vínculos a partir do ethos: para o orador convencer o público de que está qualificado para falar sobre o assunto, é preciso, segundo Aristóteles, evocar o caráter de autoridade. O conceito de ethos é trazido à tona pelo autor para se referir 
sobre traços específicos de quem fala, lugar privilegiado do discurso. Na filosofia da linguagem, o ethos se traduz como os traços característicos de um grupo, do ponto de vista social e cultural, que o diferencia de outros, significando, assim, um modo de ser, um caráter particularizado. Há, portanto, a indicação do comportamento do homem dando origem à palavra ética. Por isso, etimologicamente, a palavra ethos tem origem grega e significa valores, ética e harmonia. É o conjunto de hábitos e ações que visam o bem comum de uma determinada comunidade. Ainda mais especificamente, a palavra ethos significava para os gregos, a "morada do homem", isto é, a natureza. Em lugar da ordenação observável no ciclo natural das coisas (as marés ou as fases da lua, por exemplo), a cultura promove a sua própria ordenação ao estabelecer normas e regras de conduta que devem ser observadas por cada um de seus membros. Sendo assim, os gregos compreendiam que o homem habita o ethos enquanto a expressão normativa da sua própria natureza. A noção de uma retórica dos vínculos a partir do ethos nos convoca compreender aproximações "éticas" entre instituições. Diante dos discursos sobre responsabilidade social, cultura organizacional "verde", premissas de menos impactos ambientais, a vinculação a partir da noção de ethos parece nos fazer questionar sobre que tipo de disposição discursiva é acionada diante destas vinculações.

\section{A RETÓRICA DOS VÍNCULOS ENCENADA NO ROCK IN RIO}

Uma das premissas deste artigo é rascunhar esboços de interpretação a partir do conceito de retórica dos vínculos, como desenvolvemos até aqui. Neste caso, levando em consideração a dimensão de relevância dentro da cultura do entretenimento do Brasil, tomamos como objeto, para configuração analítica, o Rock in Rio, festival de música originado no Brasil, idealizado pelo empresário brasileiro Roberto Medina e realizado pela primeira vez em 1985. Originalmente organizado no Rio de Janeiro, de onde vem o nome, tornou-se um evento de repercussão mundial e, em 2004, teve a sua primeira edição fora do País, rumando para Lisboa, em Portugal. Ao longo da sua história, o Rock in Rio teve dez edições, quatro no Brasil, quatro em Portugal e duas na Espanha. A última edição (a qual usaremos como materialidade interpretativa) ocorreu nos dias 23, 24, 25, 29, 30 de setembro e nos dias 1 e 2 de outubro de 2011 na cidade do Rio de Janeiro. Para que possamos olhar o evento Rock in Rio através da análise dos vínculos, é necessário adentrar em sua ontologia, sua 
engrenagem, como forma de compreender e levantar hipóteses de análise mais consistentes.

Antes de identificarmos os tipos de vinculações encenadas no evento, chamamos atenção para descortinarmos quem é a instituição que realiza o Rock in Rio, que articula os vínculos analisáveis, funciona como mediadora dos interesses e estratégias institucionais. Neste sentido, a primeira questão a ser apresentada na verificação da retórica dos vínculos no Rock in Rio é entender que a gênese deste evento está articulada ao campo da publicidade, através da agência de publicidade Artplan, fundada em 1967 pelo empresário Roberto Medina - idealizador do Rock in Rio. A empresa é uma das vinte maiores agências de publicidade do País e se diz "a pioneira em propaganda-acontecimento, propaganda-além-da-propaganda, comunicação $360^{\circ}$ ". A Artplan está incorporada ao Grupo Artplan, assim como as empresas Mohallem/Artplan, Dream Factory, Dream Factory Sports, Dream Factory Digital, Better World e Rock in Rio.

Nesta breve aproximação com a Artplan, já identificamos que o Rock in Rio é uma empresa dentro da organização do grupo, funciona como uma espécie de "opção" do menu de investimentos da organização, que tem como prioridade, o foco na área de lazer, entretenimento e esportes. O Rock in Rio virou empresa com presidente, sede no Rio e operações em Madri e Lisboa. Dentro do grupo Artplan, está articulado à Dream Factory ${ }^{5}$, outra empresa do grupo, especializada em marketing de entretenimento, responsável pela produção do Rock in Rio no Brasil, Espanha e Portugal e também por $70 \%$ das ativações de publicidade promovidas no festival.

\section{OBSERVAÇÕES DAS RELAÇÕES INTRA-INSTITUCIONAIS}

Uma questão, portanto, que é preciso ser debatida na análise da retórica dos vínculos são as naturezas de articulações que viabilizam a realização do evento. Quem, de fato, é a responsável pela produção do evento, a quem se articula? Um

\footnotetext{
${ }^{5}$ De acordo com o site da empresa disponível em www.rockinrio.com.br, "a Dream Factory, aposta no conceito de brand experience para gerar conexões emocionais entre consumidores e empresas. Comandada pelo irmão de Roberta Medina, Jomar Júnior, e por Duda Magalhães, a agência criou o projeto da Árvore de Natal da Bradesco Seguros e Previdência, que há 15 anos enfeita a Lagoa Rodrigo de Freitas, no Rio de Janeiro, e já é o terceiro principal evento do Rio. Ainda na Cidade, é responsável pelo Carnaval de Rua (2010 e 2011), Coca-Cola Vibezone, Roda Skol, Roda Rio 2016, Maratona do Rio e Corrida da Ponte Rio-Niterói”.
} 
primeiro movimento de interpretação, portanto, é de ordem intra-institucional. Ou a tentativa de compreender como se dão as relações entre as empresas ou grupos que se acionam. Nesta primeira empreitada analítica, é preciso compreender as "expertises" de cada uma das empresas, qual o foco delas, nas áreas específicas de produção e realização do evento. De forma mais generalista, a observação intra-institucional serve para compreender a "solidez" do terreno em que se ancoram as disposições para a realização do evento.

No caso específico do Rock in Rio, há, digamos, uma “empresa guardachuva" que alicerça as disposições econômicas para a viabilização: a agência de publicidade Artplan. No entanto, é preciso “expertise" ("know-how") ou modo-defazer do evento. Por isso, a empresa responsável pela infra-estrutura ligada às disposições materiais, que gerencia montagem de palco, articulações de espaços, cenografias, banheiros, gestão de ambientes, entre outros tópicos, é a Dream Factory. Naturalmente, numa observação do cotidiano da gestão de produção de eventos, a Dream Factory seria a empresa que "põe a mão na massa”, articula toda a logística para que o evento seja "edificado", construído. É a empresa Dream Factory, no caso específico do Rock in Rio, quem "levanta a tenda" do evento e o coloca para funcionar.

O que cabe, então, para a "empresa" Rock in Rio propriamente dita? A direção artística do evento: escalação de artistas, contrato de atrações, formação de "line ups" e gestão de imagem do evento em si. Do ponto de vista midiático, é a empresa Rock in Rio quem contrata assessoria de imprensa, relações públicas, agências de redes sociais e conteúdos digitais e afins. Uma análise, primeiramente, intra-institucional serve justamente para compreender as engrenagens de realização do evento, articulações possíveis capazes de orientar um segundo momento de análise, que é a investigação sobre a retórica dos vínculos propriamente dita. Em síntese, a observação das vinculações intra-institucionais no Rock in Rio se ancora na progressão abaixo:
Agência de publicidade Artplan
(viabilização econômica)
$\rightarrow$ Empresa Dream Factory
(logística)
$\rightarrow$ Empresa Rock in Rio (direção artística)

Para a análise da retórica dos vínculos de um evento como o Rock in Rio, depois da observação intra-institucional, partimos para a determinação das tipologias 
de viabilização do Rock in Rio para que possamos chegar às marcas propriamente ditas. A questão agora já é extra-institucional e se angaria nas instituições/marcas que vão se aproximar de um evento através de patrocínios ou apoios. Como atividade analítica, é preciso realizar a descrição das tipologias de dispositivos viabilizadores do evento para que se possa compreender que relações são construídas entre marcas e instituições. No caso do Rock in Rio, as formas de patrocínio do evento se davam nas seguintes tipologias:

a) Patrocínio institucional - Organizações do poder público municipal e estadual que agem como viabilizadores contextuais do evento

b) Patrocínio master - Empresa que detém a maior cota de patrocínio e adquire "regalias" nas suas estratégias no evento, funciona como a instituição parceira que usa o evento que patrocina como ação de relacionamento com clientes e colaboradores, sobretudo, na criação de espaços VIPs e privilegiados

c) Patrocínios - Marcas que pagam cotas para realização de ações de publicidade e marketing

d) Media partners - Tradução de "parceiros de mídia" que funcionam como grupos comunicacionais que "apóiam" o evento, ganham lounges e espaços específicos para ações de marketing e relacionamento

e) Apoios - Marcas de segmentos diversos que prestam serviços de alimentação, turismo, informação, transporte, entre outros, de forma oficial no evento

De acordo com dados oficiais do Rock in Rio (www.rockinrio.com.br), o investimento para a realização do evento foi de $\mathrm{R} \$ 90$ milhões. Destes, $\mathrm{R} \$ 55$ milhões se configuraram em venda de patrocínio, licenciamentos, direitos de transmissão e internet. A principal estratégia foi aproveitar o forte capital de relacionamento da agência de publicidade Arplan com seus clientes. Tanto que uma parte do portfólio da agência - como as marcas Niely (Cosmético), Leader (loja de departamento), Correios e Estácio (grupo educacional) - se integrou ao festival como apoiadora para imprimir sua marca no evento.

Patrocinador master, o banco Itaú ancorou a cota máxima para estrelar o “protagonismo" no cenário. O valor da negociação não foi relevado, mas a cota inicial era de R\$ 12 milhões, enquanto para os outros cinco patrocinadores foi de R\$ 7 milhões cada uma. Marcas de refrigerantes Coca-Cola, operadora de telefonia Claro, 
marca de cerveja Heineken, de goma de mascar Trident e de automóveis Volkswagen foram patrocinadoras. Outras 15 marcas entraram como apoiadoras oficiais: Bob's (alimentação), Botequim Informal (bebida), Chilli Beans (moda e acessórios), Correios (correspondência postal), Ipiranga (postos de combustíveis), Leader (loja de departamento), Lojas Americanas (loja de departamento), Niely (cosmético), Philips (eletrônicos), Redecard (transações comerciais), Souza Cruz (cigarros), Submarino (ecommerce), Taco (moda), TAM Viagens (turismo) e Wizard (educação). O evento contou ainda com três apoiadores institucionais - Estácio (educação), Governo do Estado do Rio de Janeiro (poder público estadual) e Prefeitura do Rio (poder público municipal) - e seis parceiros de mídia - Editora Globo, Multishow, O Globo, Rádio Mix, Sky e TV Globo.

A análise realizada determinou todas as vinculações de marcas no Rock in Rio a partir do cruzamento entre a natureza de patrocínio, a estratégia de performatização adotada no evento e as dinâmicas discursivas oriundas desta performatização. Destacaremos, a seguir, os resultados mais relevantes, evidenciando as relações prementes entre os vínculos e as instituições.

\section{RETÓRICA DOS VÍNCULOS A PARTIR DO LOGOS}

Como observamos anteriormente, uma retórica dos vínculos a partir do logos configura num tipo de vinculação que evoca a ideia de "retorno" financeiro. A noção de nos aciona compreender as aproximações entre instituições diante de uma premissa econômica. A performatização de vínculos entre marcas a partir da noção de logos prevê investigar o macro-contexto da economia em que estão inseridas. Marcas se vincularam ao Rock in Rio em função de retorno financeiro, naturalmente. Não somente financeiro, claro, mas nesta primeira etapa, agruparemos as instituições que se alinharam ao Rock in Rio a partir da noção retórica de Aristóteles do logos, da racionalidade material. Segundo dados presentes no site do evento, no ramo alimentício, a rede de sanduíches Bob's vendeu 448 mil hambúrgeres ao total. A marca de alimentos Spoleto, rede de massas, vendeu 25.522 refeições e alcançou índice $30 \%$ maior do que projetado inicialmente. A média de venda das lojas da rede é de 555 refeições dia e, no evento, este número chegou a 4,5 mil. No segmento de bebidas, o balanço da marca de cerveja Heineken se ancora não só no retorno financeiro, mas também, na circulação da marca - notadamente em concorrência com 
as cervejas da "cartela" da AmBev, Skol e Brahma. Ao longo dos sete dias, a Heineken vendeu 700 mil litros de chope na Cidade do Rock, num total de 1,7 milhão de copos comercializados.

Destacamos que a retórica dos vínculos a partir do logos se dá não somente em patrocinadores. O evento como um epicentro de negócios de produtos licenciados também articula um olhar sobre retórica do logos. As 35 lojas, quiosques e diversos pontos de venda espalhados pelo Parque Olímpico da Cidade do Rock comercializaram produtos licenciados, como máquina digital da Kodak, MP-4 da marca Growing, pendrive e mídias da Youts (marca da Microservice). Os licenciamentos foram oportunidades importantes para marcas como Dr. Cooler (recipiente térmico para 12 latas), Dover-Roll (capa de chuva de bolso), Oxford (canecas de porcelana), Mariner (relógios), Yang Dong (porta CD/DVD), Bel Fix (patins e kit frescobol), TK3 (bicicleta), Embramold (copos e pratos em acrílico), Carioquez (jóias em prata), entre outras presentes com pontos de venda no festival.

\section{RETÓRICA DOS VÍNCULOS A PARTIR DO PATHOS}

A noção de uma retórica dos vínculos a partir do pathos nos direciona para as aproximações entre instituições diante de dispositivos emocionais. Marcas se vinculam a outras não somente em função de retornos financeiros. Está em jogo, também, o empréstimo emocional dos discursos, as performatizações emocionais. Mais de 50 produtos licenciados pelo Rock in Rio reforçaram esta retórica de vinculação emocional. São marcas escolhidas pelo evento como capazes de agregar valor simbólico e afetivo ao Rock in Rio. Tênis da marca Converse (largamente difundido entre jovens e indies), camisetas da Reserva (marca de moda de alto poder de consumo ligada à cultura surf e jovem), perfume da Paco Rabanne (perfumaria que se configura num dos alicerces do "odor masculino chique"), mochilas e cartucheiras da Wollner e relógios da Technos Mariner até as séries especiais dos automóveis Gol e Fox - Rock in Rio, da Volkswagen, podem ser elencados.

Uma das ações de estratégia retórica de vínculo através do pathos foi capitaneada pela marca de goma de mascar Trident, da Kraft Foods. Durante o Rock in Rio, através de um equipamento especial de fotografia, conseguiu flagrar mais de duas mil risadas na multidão que lotou o evento, entre os dias 23 e 25 de setembro. A ação foi postada na fanpage da marca na rede social Facebook, para que 
consumidores "curtissem" a marca. No dia 29 de setembro, a Trident reuniu cerca de 500 pessoas para montar uma gargalhada coletiva na Cidade do Rock.

Outra ação de vinculação retórica emocional entre o evento Rock in Rio e a marca Trident foi a cabine Trident Powered by YouTube, um local vermelho inspirado nos telefones públicos londrinos, em que o público teve a oportunidade de se sentir "uma estrela da música". Isso porque, a "instalação" permitia gravar mensagens e compartilhá-las com o mundo por meio das redes sociais. Os "interessados" tocavam uma guitarra invisível e através de uma tecnologia que possibilita a produção de sons apenas com a utilização de um par de luvas especiais, a pessoa "aparecia" tocando levadas pop, rock e heavy metal. Todas as performances foram compartilhadas por meio do canal Trident Brasil no You Tube e também nas redes sociais (Facebook e Twitter).

\section{RETÓRICA DOS VÍNCULOS A PARTIR DO ETHOS}

Uma retórica dos vínculos a partir do ethos nos convoca entender aproximações "éticas" entre instituições. No Rock in Rio, instituições se vincularam ao evento a partir dos discursos sobre responsabilidade social, cultura organizacional sustentável, premissas de menos impactos ambientais. Neste sentido, observar as retóricas dos vínculos a partir do ethos nos convoca a compreender os enlaces entre o evento e o poder público. Na aproximação com a Prefeitura do Rio, a Comlurb registrou, nos sete dias de Rock in Rio, 331 toneladas de resíduos. Desse total, 74 toneladas de lixo orgânico foram recolhidas e levadas para a Usina do Caju para compostagem e transformação do adubo orgânico chamado Fertilurb, utilizado pela Secretaria Municipal de Meio Ambiente no "Rio Capital Verde", programa de reflorestamento do município que recuperará 1,5 mil hectares em 2012.

Entre as principais retóricas do ethos "sustentável" é que o evento deixe legados para a cidade. O Rock in Rio deixou para o Rio de Janeiro, o Parque Olímpico da Cidade do Rock, erguido pela Prefeitura do Rio no Recreio dos Bandeirantes, em frente ao Riocentro. Orçado em R\$ 37 milhões, o parque será utilizado como área de lazer dos atletas dos Jogos Olímpicos de 2016 e será destinado também a sediar grandes eventos culturais e de entretenimento para a população. $\mathrm{O}$ terreno, de 150 mil metros quadrados, em forma de guitarra, recebeu um gramado sintético de 40 mil metros quadrados. O projeto original inclui estações de aparelhos 
para exercício, ciclovia (para esporte e lazer), playground, áreas de circulação para passeio, deques, marina e um mirante, instalado na Lagoa de Jacarepaguá.

\section{CONSIDERAÇÕES FINAIS}

Retomar os postulados sobre retórica de Aristóteles. Observar discursos institucionais. Construir bases metodológicas para a compreensão de aproximações entre organizações e marcas. Entender movimentações em torno de novos dispositivos de viabilização de eventos. Este texto integra o processo contínuo de investigação de matrizes conceituais que permitam análises ancoradas nas relações entre discursos e contextos sociais de eventos. Testamos aqui o aporte conceitual que chamamos de "retórica dos vínculos" e podemos postular algumas questões que podem ser compreendidas como ensejos sobre os rascunhos aqui apresentados. Dessa forma, apontamos os desdobramentos e os limites da noção desenvolvida. São eles:

a) Levantamos a hipótese de que a noção de "retórica dos vínculos" possa ser visualizada em outros contextos organizacionais, que não apenas aqueles limitados às encenações das marcas nos eventos. O evento é um lugar seguro onde nossas hipóteses puderam ser testadas. Outros estudos podem verificar a validade das nossas questões.

b) Apesar de nosso ponto de partida ser a confluência entre aportes teóricos da Semiótica e dos Estudos Culturais, a noção de "retórica dos vínculos" se inclina fundamentalmente para as análises largamente difundidas pelos estudos de Economia Política da Comunicação. O aprofundamento na leitura de autores desta área do conhecimento pode acarretar em novos desdobramentos para análises futuras.

c) É preciso acionar mais camadas de interpretação sobre os dados coletados, sobretudo as ancoradas em estudos sobre retórica das instituições. A validade sobre as tipologias de vínculos através das retrancas aristotélicas de logos, pathos e ethos está atrelada a premissas das próprias organizações e circunscritas a eventos analisáveis.

d) Analisar a "retórica dos vínculos" é um primeiro momento numa análise mais complexa sobre a discursividade dos eventos. A performatização dos espaços, por exemplo se configura num importante momento de futuras investigações. 


\section{REFERÊNCIAS BIBLIOGRÁFICAS}

ARISTÓTELES. Arte retórica e arte poética. 17.ed. Rio de Janeiro: Ediouro, 2005. . Retórica das Paixões. São Paulo: Martins Fontes, 2000.

BENVENISTE, E. O aparelho formal da enunciação. In: Problemas de Lingüística Geral II. Pontes: São Paulo, 1989.

. Estrutura das relações de pessoa no verbo. In: Problemas de Lingüística Geral I. Pontes: São Paulo, 1991.

. Da subjetividade na linguagem. In: Problemas de Lingüística Geral I. Pontes: São Paulo, 1991.

BORGES, J. F. As Mensagens Estratégicas das "Maiores e Melhores": A Retórica das Organizações na Web. Dissertação. Faculdade de Gestão de Negócios da Universidade Federal de Uberlândia (UFU). 2005. 169 f.

FRANÇA, V. V. O Objeto da Comunicação ou a Comunicação como Objeto. In: MARTINO, Luiz; HOHLFELDT, Antônio. Teorias da Comunicação. São Paulo: Vozes, 2004.

HALLIDAY, T. L. A retórica das multinacionais, a legitimação das organizações pela palavra. São Paulo: Summus Editorial, 1987.

LOPES, M. I. V. Pesquisa em Comunicação. São Paulo: Loyola, 2005.

MARCHIORI, M. (org). Faces da cultura e da Comunicação Organizacional. 2.ed. São Caetano do Sul: Difusão, 2008.

MICKEY, J.T. A Postmodern View of Public Relations: Sign and Reality. In: Public Relations Review. New York: NYU Press, 1997: 271-284.

VERÓN, Eliseo. La Semiosis Social: fragmentos de una teoría de la discursividade. Barcelona: Gedisa Editorial, 1996.

Dicionário das Idéias Não-Feitas. In: Fragmentos de um Tecido. São Leopoldo (RS): Editora Unisinos, 2004: 49-75.

Artigo submetido: 06/04/2013

Artigo aprovado: 21/01/2014 